\title{
Antimicrobial Activity of N-Hexane Extract of Nigella Sativa against Some Pathogenic Bacteria
}

\author{
Ayanwale 0 Abraham ${ }^{1 *}$, Adeniyi K Abdulazeez ${ }^{2}$, Oyewole 0 Seun $^{3}$ and David W Ogonna ${ }^{4}$ \\ ${ }^{1}$ Department of Microbiology, Federal University of Technology Minna, Nigeria \\ ${ }^{2}$ Department of Animal Biology, Federal University of Technology Minna, Nigeria
}

${ }^{3}$ Department of Microbiology, Obafemi Awolowo University, Nigeria

${ }^{4}$ Department of Biochemistry and Molecular biology, Obafemi Awolowo University, Nigeria

*Corresponding author: Ayanwale O Abraham, Department of Microbiology, Federal University of Technology Minna, Nigeria.

To Cite This Article: Ayanwale O Abraham, Antimicrobial Activity of N-Hexane Extract of Nigella Sativa against Some Pathogenic Bacteria. Am J Biomed Sci \& Res. 2019 - 6(5). AJBSR.MS.ID.001077. DOI: 10.34297/AJBSR.2019.06.001077.

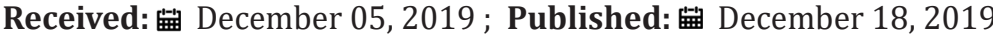

\begin{abstract}
The therapeutic properties and the constant availability of medicinal plants makes them an indispensable asset in the healthcare sector of developing countries especially in rural areas where modern healthcare systems are not readily available. This study evaluated the phytochemical compositions and antibacterial efficacy of Nigella sativa extract. The qualitative analysis of phytochemical properties was carried out using standard methods. The antimicrobial study was performed against four pathogenic bacteria (E. coli, S. aureus, Salmonella typhi, and Streptococcus pyogenes) using the agar well diffusion technics, the diameter of the zones of inhibition was read in mm, and MIC values were obtained. Results revealed the presence of saponins, anthraquinones, tannins coumarins, phenols and cardiac glycosides. The extract produced dose dependent increase inhibition S. aureus $(8.35 \pm 0.35-18.35 \pm 0.53 \mathrm{~mm})$, E. coli $(5.43 \pm 0.15-11.33 \pm 0.85 \mathrm{~mm})$ and Streptococcus pyogenes $(5.43 \pm 0.02-15.35 \pm 0.56 \mathrm{~mm})$ but was completely in active against Salmonella typhi at all concentrations $(80-200 \mathrm{mg} / \mathrm{mL})$ tested. The extract had MIC of $32,1.28 \mathrm{and} 1.28 \mathrm{mg} / \mathrm{mL}$ against Escherichia coli, Staphylococcus aureus and Streptococcus pyogenes respectively. In conclusion, N-hexane extract of $N$. sativa showed inhibitory effect on S. aureus, S. pyogenes and E. coli and thus may be useful in treating infections of which these organisms are the etiological agent.
\end{abstract}

Keywords: Antimicrobial; Phytochemicals; Nigella sativa; Microorganism

\section{Introduction}

The increasing resistance of microorganism to numbers of standard antibiotic therapies are of global problem causing enormous public health concerns [1]. Current drug's effectiveness is getting limited due to a large number of multi-drug resistant bacterial strains such as pneumococci resistant to penicillin and macrolides, methicillin-resistant staphylococci, vancomycin-resistant enterococci as well as multidrug resistant gram-negative organisms [2]. The efficacy of these synthetic chemotherapeutic agents is decreasing, they are often worsened by various side effects associated with these drugs [3]. There is, therefore, an unmet medical need to find an alternative for the treatment of various diseases caused by various microbial agents [4].

Human have relied on plants for food and medicinal purposes since ancient times and some of the chemotherapeutic agents being used today for curing diseases are of plant origin [5]. In developing countries, plants still play important role in the food, construction and health sector. The therapeutic properties and the constant availability of medicinal plants makes them and indispensable assets in the healthcare of developing countries especially in rural areas where modern healthcare system are unavailable [6]. Essential oil is part of the secondary metabolites found in higher plants. Generally, aromatic oils are useful ingredients in the cosmetics and pharmaceutical industry, they are also crucial components of soap, detergents and toothpaste $[7,8]$.

Nigella sativa is an aromatic oil producing plant belonging to the Ranunculaceae family. N. sativa is native to the Mediterranean, however it is now being cultivated in various part of the world and known by names which defer based on geographical locations. 
Among its popular names are coriander seed, black caraway seed, Love-in-a-mist, Black seed, Black Cumin, etc. [9].

$N$. sativa is believed to have high therapeutic potentials and has been reported to be effective in treating various ailments [10]. Like some medicinal plants, Black seed has been reported to possess a modulating effect on biological pathways and systems [11]. A clinical experiment carried out by $[12,13]$ concluded that $N$. sativa has a short-term effect on systolic and diastolic blood pressure, [14], reported that extracts of $N$. sativa was able to reduce triglycerides, cholesterol in clinical trials. The plant has also proven to have a stabilizing effect on man's health, boost the functionality of the immune system in fighting infectious diseases [15]. Various literatures have shown that $N$. sativa lin seeds have a lot of pharmacological activity such as bronchodilator effect, anti-inflammatory, anticancer, neuroprotective, antihistamine, hepato-protective, hypoglycemic and antiulcer activities [16-19]. The present study evaluated the antimicrobial activity of $N$. sativa against some pathogenic organism.

\section{Materials and Methods}

\section{Bacteria Strains}

Clinical isolates used for the study were obtained from Niger state General hospital, Minna. They were collected as pure isolates on agar slants and transported to Microbiology laboratory of Federal University of Technology, Minna where the experiment was performed. The bacterial pathogens used in the study are E. coli, $S$. aureus, Salmonella typhi, and Streptococcus pyogenes.

\section{Sample Collection and Authentication}

Dried seeds of $N$. sativa were purchased at a local market in Minna, Niger state. The seed was identified at the department of Plant Biology as Federal University of Technology Minna.

\section{Extraction of Plant Material}

Procedure described by [20] was used for the N-Hexane extraction of the N. sativa. The dried N. sativa seeds were grinded into powder using an electric blender. The Powered seed was then subjected to N-Hexane extraction. $10 \mathrm{~g}$ of the powder was submerged into $100 \mathrm{ml}$ of $\mathrm{N}$-Hexane and covered with a paper foil. The set up was placed in a shaker for $48 \mathrm{~h}$ at room temperature, after which it was subjected to centrifuging for 15 minutes at $2000 \mathrm{rpm}$. The supernatant was filtered off using a Whatmann filter paper 1. Ro-

\section{Result}

\section{Phytochemical composition of the N-Hexane extracts of $\mathrm{N}$. sativa}

Table 1: phytochemical constituent of Nigella sativa.

\begin{tabular}{|c|c|}
\hline Phytochemical & Inference \\
\hline Tannin & + \\
\hline Flavonoid & - \\
\hline Phlobatannin & - \\
\hline Saponin & + \\
\hline
\end{tabular}

tary evaporator set at $55^{\circ} \mathrm{C}$ was used for drying the extracts and for removing the N-Hexane solvent. The crude extract was weighed and preserved in sterile air-tight universal bottle and stored at $4^{\circ} \mathrm{C}$.

Qualitative phytochemical screening procedures previously described by Harbone $[21,22]$ were used to screen the crude extract of $N$. sativa for the presence of saponin, terpenoids, steroids, anthraquinones, tannin, flavonoid, anthraquinones and coumarins.

\section{Culture and Standardization of the Bacteria Strain}

The clinical isolates of the test organism were plated out on nutrient agar by streaking method, a loopful of the test microorganisms were then transferred into $5 \mathrm{ml}$ of nutrient broth; this was later incubated for 24 hours at $37^{\circ} \mathrm{C}$. After incubation, $0.2 \mathrm{ml}$ of the culture was transferred into $20 \mathrm{ml}$ of nutrient brought and incubated for 3-5 hours to standardize the culture to $106 \mathrm{cfu} / \mathrm{ml}$ [23].

\section{Antibacterial Assay}

The following bacteria: S. pyogenes, Salmonella typhi, Staphylococcus aureus and Escherichia coli were the species used for the experiments. Organisms were isolated by standard methods, maintained on agar plates and refrigerated until further use. The antibacterial activity of the N-hexane extract of $N$. sativa at various concentrations $(80,120,160$ and $200 \mathrm{mg} / \mathrm{ml})$ was carried out using agar-well diffusion method according to the method of CLSI [24] as described by [25]. For comparison, Ampicillin and tween 80 oil were used as positive and negative control respectively. Zones of inhibition obtained were measured with meter rule in millimeter, $5 \mathrm{~mm}$ which is the diameter of the used corn borer was subtracted from each measured inhibition zones, the final result is taken as the zones of inhibition. A broth micro-dilution method [26] was used to determine the minimum inhibitory concentration (MIC) of the extracts.

\section{Statistical Analysis}

Values were analyzed using statistical package for social science (SPSS) version 16 and presented as means \pm SE of the mean. Comparisons between different groups were carried out by oneway analysis of variance (ANOVA) followed by Duncan's Multiple Range Test (DMRT). The level of significance was set at $\mathrm{P}<0.05$.

\section{Phytochemical Screening}




\begin{tabular}{|c|c|}
\hline Alkaloid & - \\
\hline Anthraquinones & + \\
\hline Phenol & + \\
\hline Cardiac glycosides & + \\
\hline Coumarins & - \\
\hline Steroids & - \\
\hline Terpenoids & + \\
\hline
\end{tabular}

The qualitative analysis of phytochemicals in N-Hexane extract of $N$. sativa revealed the presence of saponins, anthraquinones, tannins coumarins, phenols and cardiac glycosides while flavonoids, alkaloids, steroids, phlobatannin and terpenoids were not detected (Table 1).

\section{Antibacterial activity}

Zone of Inhibition: The zone of inhibition of the organism caused by N-Hexane extracts of $N$. sativa is shown in Table 2 . The extract was completely in active against Salmonella typhi at the concentrations (80-200 mg/mL) tested. The extract produced dose dependent increase inhibition $S$. aureus $(8.35 \pm 0.35-18.35 \pm 0.53$ $\mathrm{mm})$, E. coli $(5.43 \pm 0.15-11.33 \pm 0.85 \mathrm{~mm})$ and Streptococcus pyogenes $(5.43 \pm 0.02-15.35 \pm 0.56 \mathrm{~mm})$. The standard drug (Ampicillin cause inhibition of $26.24 \pm 0.54 \mathrm{~mm}, 30.06 \pm 0.32 \mathrm{~mm}$, $23.35 \pm 0.49 \mathrm{~mm}$ and $28.92 \pm \pm 0.56 \mathrm{~mm}$ against E. coli, Staphylococcus aureus, Salmonella typhi and Streptococcus pyogenes respectively.

Table 2: Zone of inhibition ( $\mathrm{mm}$ ) of the organism caused by $\mathrm{N}$-Hexane extracts of $N$. sativa.

\begin{tabular}{|c|c|c|c|c|c|c|}
\hline \multicolumn{7}{|c|}{ Concentrations $(\mathrm{mg} / \mathrm{ml})$} \\
\hline & 80 & 120 & 160 & 200 & Ampicillin & Control \\
\hline E. coli & - & $5.43 \pm 0.15$ & $9.35 \pm 0.34$ & $11.33 \pm 0.85$ & $26.24 \pm 0.54$ & $0.00 \pm 0.00^{a}$ \\
\hline Staphylococcus aureus & $8.35 \pm 0.35$ & $11.25 \pm 0.28$ & $11.95 \pm 0.84$ & $18.35 \pm 0.53$ & $30.06 \pm 0.32$ & $0.00 \pm 0.00^{\mathrm{a}}$ \\
\hline Salmonella typhi & - & - & - & - & $23.35 \pm 0.49$ & $0.00 \pm 0.00^{a}$ \\
\hline Streptococcus pyogenes & $5.43 \pm 0.02$ & $8.95 \pm 0.38$ & $12.14 \pm 0.67$ & $15.35 \pm 0.56$ & $28.92 \pm \pm 0.56$ & $0.00 \pm 0.00^{a}$ \\
\hline
\end{tabular}

Minimum Inhibitory Concentration: Minimum Inhibitory Concentration of $\mathrm{N}-\mathrm{Hexane}$ extract of $N$. sativa are shown in Table 3. The extract had MIC of 32, 1.28 and $1.28 \mathrm{mg} / \mathrm{mL}$ against

Escherichia coli, Staphylococcus aureus and Streptococcus pyogenes respectively.

\begin{tabular}{|c|c|}
\hline Table 3: Minimum Inhibitory Concentration of N-Hexane extract of $N$. sativa. \\
\hline Organism & MIC $(\mathbf{m g} / \mathbf{m L})$ \\
\hline Escherichia coli & 32 \\
\hline Staphylococcus aureus & 1.28 \\
\hline Salmonella typhi & - \\
\hline Streptococcus pyogenes & 1.28 \\
\hline
\end{tabular}

\section{Discussion}

Generally, natural products are known to contain diverse bioactive secondary metabolites that confer to them a diverse pharmacological property [27]. The phytochemical screening of the crude extract of $\mathrm{N}$-Hexane extract of $\mathrm{N}$. sativa indicated the presence of saponins, tannins, anthraquinones, phenols coumarins, and cardiac glycosides while flavonoids, alkaloids, steroids, phlobatannin, and terpenoids were absent. This result is similar to the report of [20]. These phytochemicals have been reported for different biological activities. Therefore, the presence of these phytochemicals in $N$. sativa is an indication that these plants if properly screened would yield a drug template [28]. The dose-dependent microbial inhibition observed in this study may be due to the presence of these bioactive compounds or a synergy between members of the phytochemical compounds detected [29].

The result showed that Salmonella typhi is not inhibited by the $\mathrm{N}$-Hexane extract of $\mathrm{N}$. sativa at any of the concentration tested, indicating that the N-Hexane extract has no effect on the organism. Also, E. coli was fairly susceptible at a high concentration of the $\mathrm{N}-\mathrm{Hexane}$ extract. In general, the N-Hexane extract was found to have higher inhibitory effect on the Gram-positive bacteria tested than the Gram-negative bacteria tested. This result is similar to the study of [4] who reported that all of the N-Hexane extract of black seed was inhibitory to Gram positive bacteria than it was to Gram negative bacteria. The lack of conspicuous activity on Gram negative bacteria may be due to the structure of their cell wall which 
has permeability barrier that can reduce the active penetration of amphipathic substances into the Gram negative cell wall. Certain Gram-negative bacteria have also been associated with efflux pumps through which antibiotics are extrude from within the cell [30].

Minimum inhibitory concentration (MIC) is the lowest concentration of an extract that inhibit the visible growth of the test organism after 24hrs incubation [31-33]. The low MIC value (1.28) obtained for both $S$. aureus and $S$. pyogenes indicate that small quantity of the extract is needed to inhibit both organisms. Thus, $N$. sativa is very potent against both pathogens. However, despite the fact that the individual components of the oil, such as carvacrol, thymol, and terpenoids, have been recognized as potential antimicrobial agents, their precise mechanism of action has not been fully clarified [34].

\section{Conclusion}

The N-Hexane extract of $N$. sativa showed inhibitory effect on $S$. aureus, $S$. pyogenes and E. coli while Salmonella typhi was not inhibited at all the concentration tested, indicating that the extract is not effective against the organism. N. sativa may be useful in treating infections of which S. aureus and S. pyogenes are the etiological agent

\section{Conflicts of Interest}

The authors declare that they have no competing interests.

\section{Consent for publication}

Not applicable

\section{Authors Contributions}

This work was carried out in collaboration between all authors. All authors read and approved the final manuscript.

\section{Acknowledgment}

We would like to appreciate the technical support of Laboratory staffs of Microbiology Department Federal University of Technology Minna, Nigeria.

\section{References}

1. Edeoga HO, Okwu DE, Mbaebre BO (2005) Phytochemical constituent of some Nigerian Medicinal Plants. Afr J Biotechnol 4(7): 685-688

2. Rojas JJ, Ochoa VI, Ocampo SA, Muñoz JF (2006) Screening for antimicrobial activity of ten medicinal plants used in Colombian folkloric medicine: A possible alternative in the treatment of nonnosocomial infections. BMC Complementary Altern Med 6: 2-12.

3. Nurgali K, Jagoe RT, Abalo R (2018) Editorial: Adverse Effects of Cancer Chemotherapy: Anything New to Improve Tolerance and Reduce Sequelae? Frontiers in pharmacology 9: 245.

4. Khan AR, Kour K (2016) Wide spectrum antibacterial activity of Nigella sativa L. seeds. IOSR Journal of Pharmacy 6(7): 12-16 12.

5. Geoffrey C, Colvard MD (2012) Natural Products and Traditional Medicine: Turning on a Paradigm. Journal of natural products $75(3)$ : 514-525

6. Thomford NE, Senthebane DA, Rowe A, Munro D, Seele P, et al. (2018) Natural Products for Drug Discovery in the 21st Century: Innovations for Novel Drug Discovery. International journal of molecular sciences, 19(6): pii: E1578.

7. Edris AE (2007) Pharmaceutical and therapeutic potentials of essential oils and their individual volatile constituents: a review. Phytotherapy Research 21(4): 308-323.

8. Osuntokun OT, Ogunleye AJ (2017) Prospects of essential oils in drug discovery. Advances in Cytology \& Pathology 2(1): 17-19.

9. Nagi A, Mariana S, Rasedee A (2008) Extraction of Essential Oil from Nigella sativa Using Supercritical Carbon Dioxide: Study of Antibacterial Activity. American Journal of Pharmacology and Toxicology 3(4): 225228.

10. Zelelew D, Gebremariam A (2018) Optimization of extraction and Pharmacological activities of essential oil from Black Cumin (Nigealla sativa L.) seeds using Clevenger Distillation. Current Research in chemistry 10(1): 1-9.

11. Akloul R, Benkaci Ali F, Zerrouki M, Eppe G (2014) Composition and biological activities of the essential oil of Nigella sativa seeds isolated by accelerated microwave steam distillation with cryogenic grinding. American Journal of Essential Oils and Natural Products 1 (3): 23-33.

12. Fallah Huseini H, Amini M, Mohtashami R, Ghamarchehre ME, Sadeqhi Z, et al. (2013) Blood Pressure Lowering Effect of Nigella sativa L. Seed Oil in Healthy Volunteers: A Randomized, Double-Blind, Placebo-controlled Clinical Trial. Phytotherapy research 27(12): 1849-1853.

13. Aulia R, Siti S, Aida L, Esthika D (2017) Effect of Nigella sativa Seed Extract for Hypertension in Elderly: a Double-blind, Randomized Controlled Trial. Acta medica Indonesiana 49(4): 307-313.

14. Badar A, Kaatabi H, Bamosa A, Al-Elq A, Abou-Hozaifa B, et al. (2017) Effect of Nigella sativa supplementation over a one-year period on lipid levels, blood pressure and heart rate in type-2 diabetic patients receiving oral hypoglycemic agents: nonrandomized clinical trial. Annals of Saudi medicine 37(1): 56-63.

15. Ahmad S, Beg HZ (2013) Elucidation of mechanisms of actions of thymoquinone-enriched methanolic and volatile oil extracts from Nigella sativa against cardiovascular risk parameters in experimental hyperlipidemia. Lipids Health Dis 12: 86.

16. Lang M, Borgmann M, Oberhuber G, Evstatiev R, Jimenez K, et al. (2013) Thymoquinone attenuates tumor growth in ApcMin mice by interference with Wnt-signaling. Molecular Cancer 12(1): 41.

17. Safwan M, Bustamam A, Hadithon KA, Mediani A (2017) "Stability Study of Algerian Nigella sativa Seeds Stored under Different Conditions," Journal of Analytical Methods in Chemistry p.12.

18. Schneider Stock R, Fakhoury IH, Zaki AM, El Baba CO, Gali Muhtasib HU (2014) Thymoquinone: fifty years of success in the battle against cancer models. Drug Discovery Today 19(1): 18-30.

19. Forouzanfar F, Bazzaz BS, Hosseinzadeh H (2014) Black cumin (Nigella sativa) and its constituent (thymoquinone): a review on antimicrobial effects. Iranian journal of basic medical sciences 17(12): 929-938.

20. Ishtiaq S, M Ashraf, MQ Hayat, M Asrar (2013) Phytochemical analysis of Nigella sativa and its antibacterial activity against clinical isolates identified by ribotyping. Int J Agric Biol 15: 1511-1156.

21. Harbone JB (1984) Phytochemical Methods: A Guide to Modern Technique of Plant Analysis. ( $2^{\text {nd }}$ edition). Chapman and Hall, London 1(19): 37-168.

22. Trease GE, Evans WC (1989) Pharmacognosy (13 ${ }^{\text {th }}$ edn), English Language Book Society, Bailliere Tindall, Britain pp. 386- 480.

23. Babayi H, Kolo I, Okogun I, Ijah J (2004) The antimicrobial activities of methanolic extracts of Eucalyptus camaldulensis and Terminalia catappa against some pathogenic microorganisms. Biokemistri: Nigerian Society for Experimental Biology 16(2): 106-111.

24. CLSI (2012) Method for antimicrobial susceptibility testing of Anaerobic Bacteria; Approved standard, eight edition. CLSI document M11-A8, Wayne, PA. Clinical and Laboratory Standard Institute. 
25. Tsado NA, Lawal B, Kontagora GN, Muhammad BM, Yahaya MA, et al. (2016b) Antioxidants and Antimicrobial- Activities of Methanol Leaf Extract of Senna occidentalis. Journal of Advances in Medical and Pharmaceutical Sciences 8(2): 1-7.

26. Eloff JNA (1998) Sensitive and quick microplate method to determine the minimal inhibitory concentration of plant extracts for bacteria Planta Medica 64(8): 711-713.

27. Sheriff I Umar, Muhammad Ndako, Ali A Jigam, Sherifat F Adefolalu, Gabriel F Ibikunle, et al. (2019) Anti-plasmodial, Anti-inflammatory, antinociceptive and safety profile of Maytenus senegalensis root bark extract on hepato-renal integrity in experimental animals. Comp Clin Pathol 28(6): 1571-1579.

28. Lawal B, Ossai PC, Shittu OK, Abubakar AN (2014) Evaluation of Phytochemicals, Proximate, Minerals and Anti-Nutritional Compositions of Yam Peel, Maize Chaff and Bean Coat. International Journal of Applied Biological Research 6(2): 01-17.

29. Tsado A Ndarubu, Lawal Bashir, Ossai P Chukwudi, Jagaba Aliyu, Gwadabe N Kontagora, et al. (2016a) Antioxidants and Antimicrobial Activities of Methanol Extract of Newbouldia laevis and Crateva adansonii. Journal of Pharmacy and Allied Health Sciences 6: 14-19.
30. Nikaido H, M Vaara (1985) Molecular basis of bacterial outer membrane permeability. Journal of Microbiology Review 49(1): 1-32.

31. Yusuf AA, Lawal B, Yusuf MA, Omonije YO, Adejoke AA, et al. (2018) Free Radical Scavenging, Antimicrobial Activities and Effect of Sub-Acute Exposure to Nigerian Xylopia Aethiopica Seed Extract on Liver and Kidney Functional Indices of Albino Rat. Iranian journal of toxicology 12(3): 51-58.

32. Onukogu SC, Tsado AN, Muhammad FM, Alawode RA, Suleiman A, et al (2019) In Vitro Antioxidants, Antimicrobials and Biochemical Response of Methanol Leaf Extract of Eucalyptus camaldulensis following SubAcute Administration to Rats. Saudi J Biomed Res 4(11): 405-411.

33. Ibrahim AM, Lawal B, Abubakar AN, Tsado NA, Kontagora GN, et al. (2017) Antimicrobial and Free Radical Scavenging Potentials of N-Hexane and Ethyl Acetate Fractions of Phyllanthus Fraternus. Nigerian Journal of Basic and Applied Science 25(2): 06-11.

34. Bazaka K, Jacob MV, Chrzanowski W, Ostrikov K (2015) "Anti-bacterial surfaces: natural agents, mechanisms of action, and plasma surface modification". RSC Advances 5(60): 48739-48759. 